\title{
The Effect of Evaporative Cooling on the Activation Time of Fire Sprinklers
}

\author{
PAOLO RUFFINO and MARINO DIMARZO \\ Mechanical Engineering Department \\ University of Maryland \\ College Park, Maryland 20742, USA
}

\begin{abstract}
Arrays of fire sprinklers are installed in buildings to protect the property and their occupants against the damages of fire. When a fire occurs, the sprinkler closest to the fire location typically activates first and releases water droplets into the rising plume of hot gases. Part of these droplets is entrained by the plume and may impact on adjacent sprinklers providing evaporative cooling and thus delaying their activation. The current model that simulates the thermal response of fire sprinklers does not include this evaporative cooling effect; therefore, a new model is proposed to extend the applicability of the previous formulation. The new model includes one parameter, determined experimentally, that is associated to the evaporative cooling effect. Commercially available sprinklers are tested to assess the accuracy of the proposed model for a range of conditions (hot gas temperature and velocity, water volumetric fraction and sprinkler orientation with respect to the flow).
\end{abstract}

KEY WORDS: sprinklers activation, sprinklers skipping, evaporative cooling

\section{INTRODUCTION}

Ceiling-mounted fire sprinklers are commonly installed in residential and industrial buildings to protect the occupants and the property from the spreading of fire. Typically, these devices consist of a temperature sensitive link that plugs a water spray nozzle. When hot gases generated by the fire cause the link to fail, the sprinkler is activated and water is sprayed onto the fire.

The prediction of the activation time of a given sprinkler is based on a simple lumped capacity heat transfer model [1,2]. According to the model, the hot gases, flowing under the ceiling, heat up the sprinkler by convection. The time delay between the onset of the fire and the sprinkler activation depends on the sprinkler thermophysical characteristics, on its distance from the fire and on the fire intensity. A correction to the simple convective model can be introduced to account for the heat lost by conduction from the sprinkler to its supporting pipe and to the water within, as well as for the radiative heat gain from the fire plume $[2,3]$.

Recent experiments indicate that this model is not adequate to predict the response of an array of fire sprinklers. The model predicts reasonably well the activation of the first sprinkler, closest to the fire. However, it fails to predict the activation time for the adjacent ones. The cause for this deficiency can be related to the presence of water droplets in the gas stream. A portion of the water spray introduced by the first activated 
sprinkler is entrained by the ascending fire plume and transported to the adjacent sprinklers. The droplets deposit on the sprinklers and evaporate. The evaporative cooling effect counteracts the heating from the hot gases, thus increasing the time required by the sprinkler to activate. The current model cannot predict this effect. The purpose of this paper is to present an improved model for the thermal response of the sprinkler, that considers the evaporative cooling effect due to the water droplets in the gas stream.

\section{MODEL FORMULATION}

For this analysis, the conductive and radiant heat transfer contributions to the energy balance of the sprinkler are neglected. In the absence of water droplets (dry conditions), the lump ed capacity energy balance for the sprinkler link is written as:

$$
\rho_{S} c_{S} V \frac{d T_{S}^{D}}{d t}=h S\left(T_{G}^{D}-T_{S}^{D}\right)
$$

Equation (1) can be solved, with the initial condition $T_{S}=T_{0}$ at $t=0$, for constant gas stream temperature and velocity. The convective heat transfer coefficient for a bluff object depends on the Reynolds number raised to the 0.5 power (and consequently on the square root of the gas velocity) for values of the Reynolds number typical of fire environments [4]. The same dependence exists for cylinders in cross-flow with Reynolds numbers between 40 and 1000 [5]. Therefore, we can express the heat transfer coefficient in Eq. (1) as a function of the gas stream velocity and group all other parameters into a parameter known as the Response Time Index (RTI) $[1,2]$ to yield:

$$
\frac{T_{G}^{D}-T_{S}^{D}}{T_{G}^{D}-T_{0}}=\exp \left(-\frac{\sqrt{U}}{R T I} t\right)
$$

The superscript $D$ refers to the dry-gas conditions while the RTI is defined as:

$$
R T I=\frac{\rho_{S} c_{S} V \sqrt{U}}{h S}
$$

The RTI is a function of the thermo-physical characteristics and geometric dimensions of the sprinkler. For typical fire conditions, it can be assumed to be a constant for any given sprinkler [2].

When the gaseous stream carries water droplets, the energy balance in Eq. (1) needs to be modified to account for the energy required to evaporate the water deposited on the sprinkler link. The following assumptions are made:

- The droplets in the gas stream are at saturated liquid conditions. Therefore, the evaporative cooling per unit mass of water is equal to the latent heat of vaporization.

- The droplet mass flux and distribution is constant in time and uniform over any given cross section throughout the gas stream.

- Most of the droplets impacts the surface of the link, while some have sufficiently small inertia to move around the obstacle.

- All the water deposited on the link is assumed to evaporate.

- The water droplets are sparse in the hot gas flow, so that no droplet-droplet interactions are considered. 
The presence of the sprinkler affects the gas flow so that most of the water droplets that would have passed through the cross sectional area occupied by the link will actually deposit on it. We introduce the collection efficiency $\kappa$ to represent the fraction of water that impacts the link. Also, the impacting drops are supposed to evaporate on the link surface. This is reasonable because the droplets are sparse and the gas temperature is high. Therefore, there is little chance for significant water build-up on the link, which may lead to run-off or re-entrainment of water in the gaseous stream. An experimental study by Grissom and Wierum [6] confirms that no flooding is likely to occur over the surface under any condition investigated in our study. Correlations provided by Paleev \& Filippovich [7] and Berry \& Goss [8] indicate that any possible water build-up and consequential entrainment of water in the gas flow are negligible, as well. The resulting energy balance can be written as:

$$
\rho_{S} c_{S} V \frac{d T_{S}^{W}}{d t}=h S\left(T_{G}^{W}-T_{S}^{W}\right)-\rho_{L} U A \beta \kappa \Lambda
$$

The volumetric fraction $\beta$ is the ratio of the liquid volume in a given sample over the total sample volume. The collection efficiency $\kappa$ can be estimated by considering the Stokes' approximation applied to droplets carried by the gas stream over a cylinder in cross-flow [9]. In estimating the collection efficiency, the key parameters are the Reynolds number based on the overall gas velocity and on the droplet diameter, the ratio of the droplets and of the cylinder diameters, and the ratio of the gas and liquid densities. For the applications of concern, the collection efficiency approaches its asymptotic value of 0.97 . Therefore, $\kappa$ can be regarded as a constant in the applicable range of parameters.

The energy balance in Eq. (4) can be integrated with the initial condition $T_{S}=T_{0}$ at $t=0$ yielding the following expression:

$\frac{T_{G}^{W}-T_{S}^{W}}{T_{G}^{W}-T_{0}}=C \frac{\beta \sqrt{U}}{T_{G}^{W}-T_{0}}+\left(1-C \frac{\beta \sqrt{U}}{T_{G}^{W}-T_{0}}\right) \exp \left(-\frac{\sqrt{U}}{R T I} t\right)$

The superscript $W$ refers to the wet-gas conditions. The evaporative cooling parameter $C$ introduced in Eq. (5) is defined as:

$C=\frac{\rho_{L} A \kappa \Lambda}{S} \frac{\sqrt{U}}{h}$

The heat transfer correlation for a cylinder in cross-flow for Reynolds number in the range between 40 and 1000 [5] can be expressed as:

$h=0.52 \frac{k_{G}}{d} \operatorname{Re}_{\mathrm{d}}^{0.5} \operatorname{Pr}^{0.37}$

Noting that the various parameters or their groupings are nearly constant over the range of conditions of concern [1], the evaporative cooling parameter $C$ can be described as:

$$
C=\left(\frac{\rho_{L} \Lambda \kappa}{0.52 \pi} \frac{\mu_{G}^{0.5}}{k_{G} \rho_{G}^{0.5} \operatorname{Pr}^{0.37}}\right) \sqrt{d} \propto \sqrt{d}
$$

This means that $C$ is independent of the gas velocity and can be considered only a function of the sensor size expressed as the diameter of an equivalent cylinder.

Equation (5) yields the activation time of a sprinkler in wet conditions as: 
$t_{A}^{W}=\frac{R T I}{\sqrt{U}} \ln \left(\frac{T_{G}^{W}-C \beta \sqrt{U}-T_{0}}{T_{G}^{W}-C \beta \sqrt{U}-T_{A}}\right)$

As pointed out previously, the evaporative cooling parameter is a function of the size of the sensing element. In the case of commercial sprinklers, the geometry may be complex thus an equivalent cylindrical diameter may not be readily identifiable. Therefore, it is desirable to link the characteristic dimension of a given sprinkler to its RTI. Recall that from Eq. (3) and Eq. (7) the RTI is found to be proportional to the equivalent cylindrical diameter raised to the 1.5 exponent and to the product of the density and specific heat of the sprinkler link material. All other parameters or their combinations are nearly constant within the range of applicability. For a given size and material of the sensing element we can identify $C_{R}, R T I_{R}$ and $\left(\rho_{S} c_{S}\right)_{R}$. With this notation, the evaporative cooling parameter is then given as:

$C=C_{R}\left(\frac{R T I}{R T I_{R}}\right)^{1 / 3}\left[\frac{\rho_{S} c_{S}}{\left(\rho_{S} c_{S}\right)_{R}}\right]^{1 / 3} \approx C_{R}\left(\frac{R T I}{R T I_{R}}\right)^{1 / 3}$

This simplification is possible since the range of properties associated with the materials used in the sprinkler links results in a possible error of less than $8 \%$ when neglecting the term in squared brackets. With the appropriate reference values, which will be obtained in the following section, the evaporative cooling parameter, for any given sprinkler, is given as:

$$
C=1.3 R T I^{1 / 3}
$$

\section{EVAPORATIVE COOLING PARAMETER}

Figure 1 depicts the main portion the Evaporative Cooling Sensor Accuracy Test (ECSAT) facility. A blower placed near the outlet of the duct generates the gas flow inside the system. The air entering into the duct is heated up by a natural gas burner and then flows upward through a square duct section $(0.61 \mathrm{~m} \times 0.61 \mathrm{~m})$. A honeycomb structure, about $0.2 \mathrm{~m}$ thick and made of tightly packed steel wool, is placed in the initial portion of the duct. Its purpose is to force the gas stream to spread over the entire crosssection, as well as to obtain a more uniform temperature distribution. As the hot gas emerges from the honeycomb, it reaches the spray location. A finely atomized water spray is injected into the gas stream, simulating the effect of the activation of the primary sprinkler. A square-edged circular orifice $(0.25 \mathrm{~m}$ diameter $)$ is located about $0.49 \mathrm{~m}$ downstream of the spray. The orifice represents an abrupt restriction of the crosssectional area for the two-phase flow. The orifice induces a vena contracta in the flow, which is characterized by the near parallel streamline profile.

At the location of the vena contracta, which occurs about $0.4 \mathrm{~m}$ downstream of the orifice, the mean velocity field is parallel to the axis of the orifice. The range of velocities investigated in this study is in between 3 and $9 \mathrm{~m} / \mathrm{s}$. The flow is yet turbulent before the orifice. Additional turbulent effects at the vena contracta may also be induced by the gas jet produced by the orifice, as it mixes with the slower gases flowing downstream. Clearly, the turbulence level in the test section and the disturbances induced by the gas jet may influence the gas velocity field, in particular its alignment with the axis of the duct. Calculations [10] show that the intensity of turbulence, defined as the ratio of the fluctuating radial velocity to the mean gas velocity, is about 5 percent, which does not 


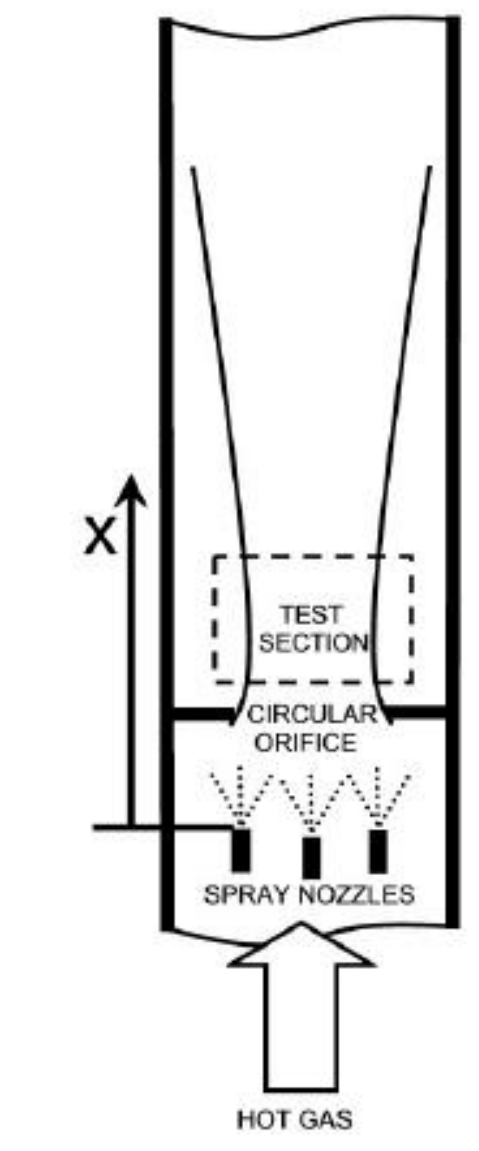

FIGURE 1 ECSAT Facility Schematic seem very significant compared to other experimental uncertainties present in this study. Also, note that typically 300 particle samples are analyzed to obtain statistically meaningful measurements, thus decreasing the inaccuracies associated with the turbulence level of the gas flow. Because of this characteristic of the flow field, the vena contracta is chosen as the test section for the sprinkler experiments. Downstream of the vena contracta, the flow spreads and returns to occupy the entire duct cross-section.

The ECSAT facility allows for the measurement of the gas velocity and the axial temperature evolution in both dry and wet conditions. This information is needed in order to determine the evaporative cooling parameter $C$.

The test section is illuminated by a 600 mW Argon-ion laser sheet. Particle Tracking Velocimetry (PTV) provides the gas velocity measurements in the cross-section [11]. Thirty measurements are made to obtain a statistically meaningful value of the droplets velocity. Note that the droplets introduced in the gas flow have a maximum volumetric mean diameter of

less than $100 \mu \mathrm{m}$. This results in a terminal velocity of about $0.24 \mathrm{~m} / \mathrm{s}$. Since the estimated gas velocity is in excess of $3.5 \mathrm{~m} / \mathrm{s}$, the measured droplets velocity lags the actual gas velocity by less than 4 percent. Neglecting this difference, we can assume that the PTV measurements provide the velocity of the gas stream. The uncertainty in the velocity measurements is about 10 percent.

Thirty-three thermocouples (type $\mathrm{K}$, with accuracy of $\pm 2^{\circ} \mathrm{C}$ ) are placed inside the duct along its axis, both before and after the test section, to measure the gas temperature distribution in the facility and monitor the conditions during the experiment. Figure 2 reports the typical temperature axial evolution, for both dry and wet conditions. It can be observed that:

- Due to the heat losses to the external environment, the gas temperature drops as the flow proceeds downstream the orifice.

- The gas temperature upstream the spray nozzle location is equal in both dry and wet conditions. 
- About $2 \mathrm{~m}$ downstream the test section, the slope of the temperature distribution for the wet case becomes equal to the temperature distribution for the dry case. This indicates that the water is completely evaporated and the temperature is affected only by the heat losses to the environment.

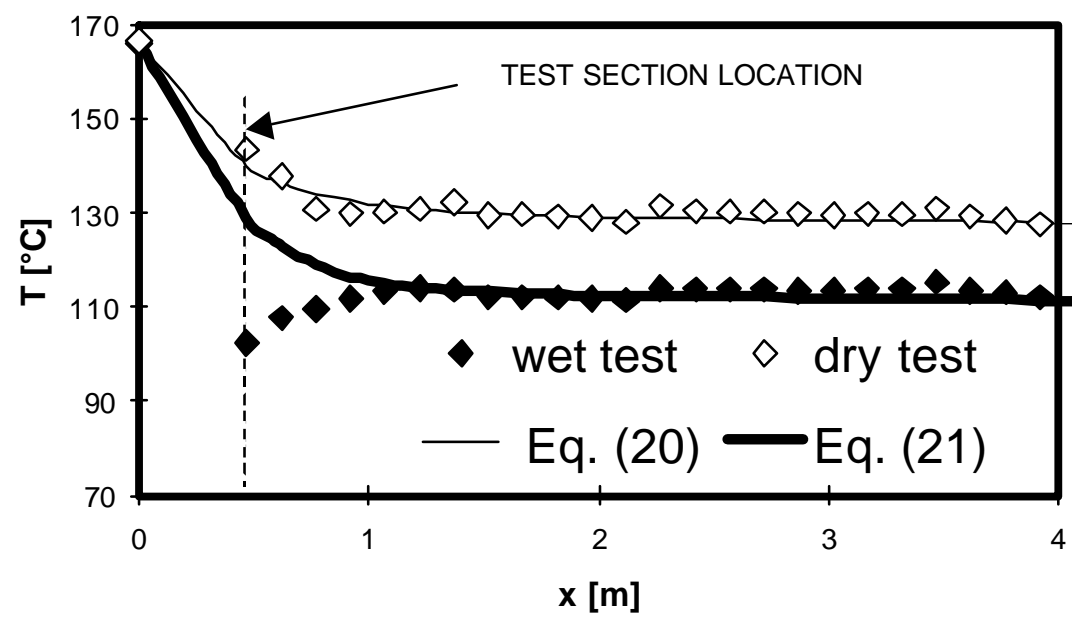

FIGURE 2 - Temperature Evolution Along the Longitudinal Axis of the ECSAT Facility.

Therefore, the thermocouple sensors measure the gas temperature at the location before the sprays and at the location after the complete evaporation of the water. To determine the gas temperature between the sprays and the location of complete evaporation of the water, some information concerning the rate of vaporization of the droplets is needed. Consider the energy balance written for the water droplets and dividing both side of the equation by the gas volumetric flow rate, one obtains:

$\rho_{G} c_{G}\left(T_{G}^{D}-T_{G}^{W}\right)=\rho_{L}\left(\beta_{N}-\beta\right) \Lambda$

The asymptotic temperature difference $\Delta T$, between the two traces in Fig. 2, is associated with the sensible heat removed from the air in order to vaporize the droplets. It can be expressed in the following form:

$\Delta T=\frac{\rho_{L} \cdot \beta_{N} \cdot \Lambda}{\rho_{G} \cdot c_{G}}$

With Eq. (13), Eq. (12) can be simplified as:

$T_{G}^{D}-T_{G}^{W}=\Delta T[1-f(x)]$

The function $f(x)$ relates the volumetric fraction at the spray nozzle location to its evolution along the duct so that:

$\beta=\beta_{N} f(x)$

Equation (4), written for a sensor wetted by water droplets yields a direct relationship between the convective heat transfer to the sensor and the latent heat associated with the vaporization of the droplets that deposit over its surface. At steady state, Eq. (4) simplifies as:

$h S\left(T_{G}^{W}-T_{S}^{W}\right)=\rho_{L} U A \beta \kappa \Lambda$ 
Considering the water volumetric fraction evolution during the evaporation process and using Eq. (6), Eq. (16) can be rearranged as:

$T_{G}^{W}-T_{S}^{W}=C \sqrt{U} \beta_{N} f(x)$

By adding Eq. (14) and Eq. (17), one finds that the functional $f(x)$ can be expressed in the following form:

$$
f(x)=\frac{T_{G}^{D}-T_{S}^{W}-\Delta T}{C \sqrt{U} \beta_{N}-\Delta T}
$$

Note that $f(x)$ is equal to 1 at the spray nozzles location and is equal to zero for $x$ greater or equal to $x_{E}$, where all the water drops are evaporated. The $D^{2}$ law [12] suggests the following functional form:

$$
f(x)= \begin{cases}\left(1-\frac{x}{x_{E}}\right)^{\lambda} & \mathrm{x} \leq \mathrm{x}_{\mathrm{E}} \\ 0 & \mathrm{x}>\mathrm{x}_{\mathrm{E}}\end{cases}
$$

By plotting $T_{G}{ }^{D}-T_{S}^{W}-\Delta T$ versus $x$ one easily determines the value of $x_{E}$. Then limiting the data to the evaporative range and normalizing the abscissa as $x / x_{E}$, one can look at these data in a logarithmic plot and deduce the exponent $\lambda$ of Eq. (19). The value of this exponent is found to be 1.7 for all the data available. Note that the $\mathrm{D}^{2}$ law yields an exponent equal to 1.5. This difference can be explained if one takes into account the expansion of the jet downstream the circular orifice. This expansion produces a sharper decrease in the volumetric fraction than the one observed in a constant cross-section flow configuration.

Finally, with the exponent and the evaporation distance known, one can determine the value of the evaporative cooling parameter $C$ for all the tests. By equating Eq. (18) and Eq. (19), one can use the result to fit the wet condition data. Note that the only fitting parameter available is indeed $C$. To facilitate this process, the temperature in dry conditions is represented with an exponential fit of the available data in the following form:

$$
T_{G}^{D}(x)=\left(T_{N}-\xi\right) e^{-\gamma x}+\varphi x+\xi
$$

The constant $\varphi$ represents the slope of the trace on the right side of the plot in Fig. 2 due to the heat transfer losses to the ambient. This fit is shown in the figure with a thin continuous line.

Note that the water volumetric fraction at the nozzles is evaluated considering the water and air volumetric flow rates respectively. The database used to determine the value of the evaporative cooling parameter encompass tests with:

- velocity ranging from 3 to $7 \mathrm{~m} / \mathrm{s}$

- gas temperatures at the nozzle locations between 150 and $250{ }^{\circ} \mathrm{C}$

- volumetric fractions at the nozzles up to $19 \mathrm{ppm}$.

As expected from Eq. (8), the value of the evaporative cooling parameter $C$ is constant for all the tests and its numerical value is equal to $6 \mathrm{~K}-\mathrm{s}^{1 / 2} / \mathrm{m}^{1 / 2}$ when the temperature is measured with thermocouple imbedded in an aluminum cylinder of $6.4 \mathrm{~mm}$ in diameter. These are the reference values previously used to obtain Eq. (11). 
It follows that the interpolation describing the gas temperature in wet conditions is given by substituting Eq. (19) into Eq. (14) and using Eq. (20) for $\mathrm{T}_{\mathrm{G}}{ }^{\mathrm{D}}$ to yield:

$$
T_{G}^{W}(x)= \begin{cases}T_{G}^{D}-\Delta T \cdot\left[1-\left(1-\frac{x}{x_{E}}\right)^{1.7}\right] & \mathrm{x} \leq \mathrm{x}_{\mathrm{E}} \\ T_{G}^{D}-\Delta T & \mathrm{x}>\mathrm{x}_{\mathrm{E}}\end{cases}
$$

It is reasonable to presume that this approach provides a good representation of the hot gas temperature trend. In particular, the intersection of the temperature profile given by Eqs. (20) and (21) (represented by the thick line) with the vertical dashed line in Fig. 2 provides the gas temperature at the test section in dry and wet conditions respectively.

\section{COMMERCIAL SPRINKLER DATA}

In order to assess the capability of the new model to predict the activation time of a sprinkler in the presence of water droplets, an extensive experimental campaign is conducted in the ECSAT facility using four different types of sprinklers. Figure 3 depicts the sprinklers used in this study that are identified as:

a) Standard response solder Element sprinkler (SE) with $\mathrm{T}_{\mathrm{A}}=72{ }^{\circ} \mathrm{C}$;

b) $5 \mathrm{~mm}$ bulb Standard Response sprinkler (SR) with $\mathrm{T}_{\mathrm{A}}=68{ }^{\circ} \mathrm{C}$;

c) $3 \mathrm{~mm}$ bulb Quick Response sprinkler (QR) with $\mathrm{T}_{\mathrm{A}}=68{ }^{\circ} \mathrm{C}$;

d) Quick response solder Element sprinkler $(\mathrm{QE})$ with $\mathrm{T}_{\mathrm{A}}=74{ }^{\circ} \mathrm{C}$.

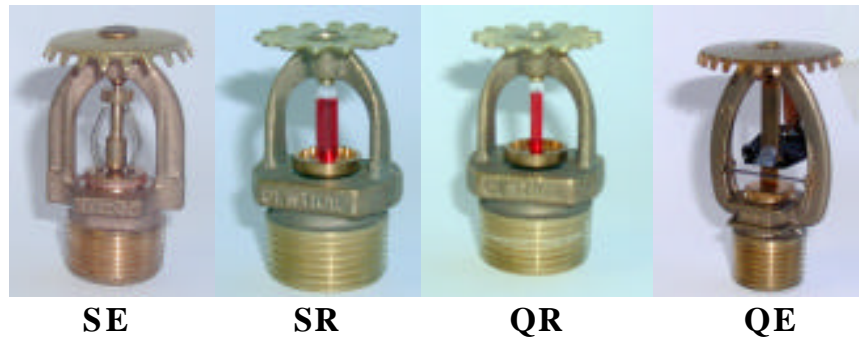

FIGURE 3 Sprinklers Used in This Study

Table 1 summarizes the values of the RTI obtained from Eq. (2) for each sprinkler type while testing the devices in dry conditions. The orientation with the sprinkler frame orthogonal to the flow (the flow hits the link and the two frame arms simultaneously) is used in conditions A, B, D and E. The orientation with the frame parallel to the flow (the flow hits one frame arm, then the link then the other frame arm) is used in conditions $C$ and F. As one may notice, two orientations have been considered for the first three types of sprinklers, while the orientations considered for the QE type are three. This is necessary since the sprinkler type QE has only one plane of symmetry through its vertical axis. In case $\mathrm{D}$ the flow hits the two frame arms and then the sensing element; in case $\mathrm{E}$ the flow hits first the sensing element and then the two frame arms and finally in case $\mathrm{F}$ the flow hits first one frame arm, then the sensing element and finally the second frame arm. For all these sprinklers, in all cases, mounting the sprinkler head on a plastic support (PTFE Teflon) minimizes the effect of conduction heat transfer. 
TABLE 1 - RTI $\left[\mathrm{m}^{1 / 2} \mathrm{~s}^{1 / 2}\right.$ ] of the sprinklers used in the study

\begin{tabular}{|c|c|c|c|}
\hline & Condition A & Condition B & Condition C \\
\hline SE sprinkler & $109 \pm 13$ & $108 \pm 8$ & $114 \pm 9$ \\
\hline SR sprinkler & $98 \pm 13$ & $90 \pm 10$ & $133 \pm 8$ \\
\hline QR sprinkler & $41 \pm 4$ & $39 \pm 3$ & $46 \pm 5$ \\
\hline
\end{tabular}

\begin{tabular}{|c|c|c|c|}
\hline & Condition D & Condition E & Condition F \\
\hline QE sprinkler & $27 \pm 2$ & $27 \pm 2$ & $27 \pm 1$ \\
\hline
\end{tabular}

The sprinklers are tested under a set of six different conditions as listed in Table 2. The tests performed in this study are similar to the standard plunge test [13] with the notable exception that water droplets are present in the air stream. Conditions B, D, E and F are close to those prescribed for the standard plunge test [13]. However, the water volumetric fraction must be low enough to avoid sprinkler skipping (i.e. failure to activate). In conditions $\mathrm{A}$ and $\mathrm{C}$, a larger amount of water is used; in order to obtain the sprinkler activation, the gas temperature is also raised. Condition B is achieved with one spray nozzle generating droplets with volumetric mean diameter of $82 \mu \mathrm{m}$ [14], while conditions A, C, D, E and F are achieved with three smaller nozzles on a triangular pitch, generating droplets with volumetric mean diameter of $65 \mu \mathrm{m}$ [14]. A minimum of ten sprinklers is used for each experimental data point.

TABLE 2 - Conditions for the sprinkler tests

\begin{tabular}{|c|c|c|c|}
\hline & Condition A & Condition B & Condition C \\
\hline Gas temperature in dry conditions $\left[{ }^{\circ} \mathrm{C}\right]$ & 178 & 140 & 156 \\
\hline Gas temperature in wet conditions $\left[{ }^{\circ} \mathrm{C}\right]$ & 164 & 127 & 134 \\
\hline $\begin{array}{c}\text { Continuous sensor temperature } \\
\text { measured in wet conditions }\left[{ }^{\circ} \mathrm{C}\right]\end{array}$ & 96 & 97 & 79 \\
\hline Initial \& ambient temperature $\left[{ }^{\circ} \mathrm{C}\right]$ & 32 & 29 & 22 \\
\hline Gas velocity $[\mathrm{m} / \mathrm{s}]$ & 3.8 & 3.5 & 3.7 \\
\hline Water volumetric fraction $[\mathrm{ppm}]$ & 7 & 4 & 5 \\
\hline
\end{tabular}

\begin{tabular}{|c|c|c|c|}
\hline & Condition D & Condition E & Condition F \\
\hline Gas temperature in dry conditions $\left[{ }^{\circ} \mathrm{C}\right]$ & 156 & 163 & 168 \\
\hline Gas temperature in wet conditions $\left[{ }^{\circ} \mathrm{C}\right]$ & 133 & 150 & 151 \\
\hline $\begin{array}{c}\text { Continuous sensor temperature } \\
\text { measured in wet conditions }\left[{ }^{\circ} \mathrm{C}\right]\end{array}$ & 84 & 99 & 95 \\
\hline Initial \& ambient temperature $\left[{ }^{\circ} \mathrm{C}\right]$ & 28 & 31 & 33 \\
\hline Gas velocity $[\mathrm{m} / \mathrm{s}]$ & 3.9 & 3.9 & 3.7 \\
\hline Water volumetric fraction $[\mathrm{ppm}]$ & 5 & 4 & 5 \\
\hline
\end{tabular}

Typical results show that the time of activation under wet conditions is three to four times longer than in the dry conditions. The experimental scatter is quite significant. Table 3 summarizes all the findings. Each data point represents the average of ten test results performed in identical conditions. 
Consider the first three types of sprinkler (SE, SR, QR). For conditions A and B, the model predictions are in reasonable agreement with the experiments, with discrepancies within one standard deviation of the experimental data. In condition $\mathrm{C}$, one of the two frame arms is upstream of the sprinkler link, shielding it from the incoming water droplets. Therefore, a significant fraction of the water droplet impacts the frame arm rather than the link, reducing the evaporative cooling effect on the link. This is particularly true for the SR sprinkler, whereas the SE sprinkler does not show any major effects of orientation on the activation time. The reason for this behavior can be found by looking at the geometrical configuration of the SE sprinkler, which has a solder element at the base of the sprinkler. Therefore, conductive heat transfer between the upstream frame arm and the base compensates for the reduced evaporative cooling. For the bulb type sprinkler (SR), thermal conductivity plays a negligible role because the glass bulb is not a good thermal conductor. Therefore, a shorter activation time is observed experimentally due to the reduced amount of evaporative cooling. In Table 3 , this instance is highlighted with bold characters for ease of identification.

TABLE 3 - Sprinkler activation times in [s]: model predictions and experiments

\begin{tabular}{|r|c|c|c|}
\hline & Condition A & Condition B & Condition C \\
\hline SE sprinkler & \multicolumn{3}{|c|}{} \\
\hline $\mathrm{t}_{\mathrm{A}}{ }^{\mathrm{D}}$ measured & $19 \pm 2$ & $29 \pm 3$ & $29 \pm 3$ \\
\hline $\mathrm{t}_{\mathrm{A}}{ }^{\mathrm{W}}$ measured & $91 \pm 20$ & $90 \pm 13$ & $135 \pm 48$ \\
\hline $\mathrm{t}_{\mathrm{A}}{ }^{\mathrm{W}}$ calculated & $89 \pm 21$ & $95 \pm 14$ & $122 \pm 9$ \\
\hline SR sprinkler & & & $29 \pm 2$ \\
\hline $\mathrm{t}_{\mathrm{A}}{ }^{\mathrm{D}}$ measured & $13 \pm 1$ & $19 \pm 3$ & $\mathbf{7 3} \pm \mathbf{8}$ \\
\hline $\mathrm{t}_{\mathrm{A}}{ }^{\mathrm{W}}$ measured & $54 \pm 21$ & $47 \pm 14$ & $\mathbf{1 1 5} \mathbf{7}$ \\
\hline $\mathrm{t}_{\mathrm{A}}{ }^{\mathrm{W}}$ calculated & $53 \pm 10$ & $53 \pm 8$ & $10 \pm 1$ \\
\hline $\mathrm{t}_{\mathrm{A}}{ }^{\mathrm{D}}$ measured & $6 \pm 1$ & & $24 \pm 3$ \\
\hline $\mathrm{t}_{\mathrm{A}}{ }^{\mathrm{W}}$ measured & $17 \pm 4$ & $18 \pm 3$ & $26 \pm 2$ \\
\hline $\mathrm{t}_{\mathrm{A}}{ }^{\mathrm{W}}$ calculated & $15 \pm 2$ & $19 \pm 4$ & \\
\hline
\end{tabular}

\begin{tabular}{|r|c|c|c|}
\hline & Condition D & Condition E & Condition F \\
\hline QE sprinkler & & & \\
\hline $\mathrm{t}_{\mathrm{A}}{ }^{\mathrm{W}}$ measured & $5 \pm 1$ & $4 \pm 1$ & $4 \pm 1$ \\
\hline $\mathrm{t}_{\mathrm{A}}{ }^{\mathrm{W}}$ measured & $20 \pm 3$ & $10 \pm 1$ & $9 \pm 1$ \\
\hline $\mathrm{t}_{\mathrm{A}}{ }^{\mathrm{W}}$ calculated & $18 \pm 2$ & $9 \pm 2$ & $10 \pm 2$ \\
\hline
\end{tabular}

For the QE and QR type sprinklers, the analysis of the data presented in Table 1 and 3 shows that the RTI of the sprinkler does not vary significantly with the orientation of the sprinkler frame and that, for all the test conditions, the experimental values are reasonably well predicted by the mo del. 


\section{CONCLUSIONS}

A model for the prediction of the sprinkler activation time is proposed. The model includes the evaporative cooling effect due to the water droplets present in the gas stream. The water droplets are introduced upon the activation of the first sprinkler. The model is based on two parameters, $R T I$ and $C$. The $R T I$ is known from the sprinkler manufacturers or it can be determined experimentally with the plunge test [14]. The parameter $C$ is evaluated once the $R T I$ is known.

Four types of sprinklers, with RTI ranging from 25 to $141 \mathrm{~m}^{1 / 2} \mathrm{~s}^{1 / 2}$, are tested under various conditions to validate the model. The model predictions are in good agreement with the measurements, within the scatter associated with the experimental data. In some particular conditions, the orientation of the sprinkler frame with respect to the flow may cause the model to overestimate the activation time for the standard response glass bulb type sprinklers since one of the frame arms may shield the link from the water droplets thus reducing the evaporative cooling effect.

\section{ACKNOWLEDGEMENTS}

The Building and Fire Research Laboratory of the National Institute of Standards and Technology provided the financial support for this research. The encouragement and technical support of Drs. Evans and McGrattan are greatly appreciated.

\section{NOMENCLATURE}

A cross-sectional area of the sprinkler link orthogonal to the flow, $\mathrm{m}^{2}$

c specific heat, $\mathrm{J} \mathrm{kg}^{-1}{ }^{\circ} \mathrm{C}^{-1}$

$\mathrm{C} \quad$ evaporative cooling parameter, ${ }^{\circ} \mathrm{C} \mathrm{s}^{1 / 2} \mathrm{~m}^{-1 / 2}$

d characteristic diameter of the sprinkler link, $m$

$\mathrm{f}(\mathrm{x}) \quad$ volumetric fraction functional, see Eq. (15)

$\mathrm{h} \quad$ convective heat transfer coefficient, $\mathrm{W} \mathrm{m}{ }^{-2}{ }^{\circ} \mathrm{C}^{-1}$

$\mathrm{k}$ thermal diffusivity, $\mathrm{W} \mathrm{m}^{-1}{ }^{\circ} \mathrm{C}^{-1}$

Pr Prandtl number $\operatorname{Pr}=\mu_{\mathrm{G}} \mathrm{c}_{\mathrm{G}} / \mathrm{k}_{\mathrm{G}}$

$\operatorname{Re}_{\mathrm{d}} \quad$ Reynolds number based on the simulated link diameter $\operatorname{Re}_{\mathrm{d}}=\rho_{\mathrm{G}} \mathrm{U} d / \mu_{\mathrm{G}}$

RTI Response Time Index; see Eq. (3), $\mathrm{m}^{1 / 2} \mathrm{~s}^{1 / 2}$

$\mathrm{S} \quad$ surface area of the sprinkler link, $\mathrm{m}^{2}$

$\mathrm{t}$ time, $\mathrm{s}$

$t_{\mathrm{A}} \quad$ sprinkler activation time, $\mathrm{s}$

$\mathrm{T}$ temperature, ${ }^{\circ} \mathrm{C}$

$\mathrm{T}_{\mathrm{A}} \quad$ sprinkler activation temperature, ${ }^{\circ} \mathrm{C}$

$\mathrm{U} \quad$ gas velocity, $\mathrm{m} \mathrm{s}^{-1}$

$\mathrm{V} \quad$ volume of the sprinkler link, $\mathrm{m}^{3}$

$\mathrm{x} \quad$ axial coordinate along the duct measured from the location of spray nozzles, $\mathrm{m}$

$\mathrm{x}_{\mathrm{E}} \quad$ axial position along the duct where all the water is vaporized, $\mathrm{m}$

Greek

$\beta \quad$ water volumetric fraction, $\mathrm{ppm}$

$\Delta \mathrm{T} \quad$ asymptotic temperature difference, see Eq. (13), ${ }^{\circ} \mathrm{C}$

$\kappa \quad$ collection efficiency; see Eq. (4)

$\lambda, \gamma, \xi, \varphi$ constants in Eqs. (19) and (20) 
$\Lambda \quad$ latent heat of vaporization of water, $\mathrm{J} \mathrm{kg}^{-1}$

$\mu \quad$ kinematic viscosity, $\mathrm{kg} \mathrm{m}^{-1} \mathrm{~s}^{-1}$

$\rho \quad$ density, $\mathrm{kg} \mathrm{m}^{-3}$

Subscript and Superscripts

$0 \quad$ initial time

D dry conditions

G gas

$\mathrm{L} \quad$ liquid

$\mathrm{R} \quad$ reference case; see Eq. (10)

S sprinkler link

$\mathrm{N} \quad$ at the location of the water nozzles

W wet conditions

\section{REFERENCES}

1. Heskestad, G. and Smith, H.F., "Investigation of a New Sprinkler Sensitivity Approval Test: the Plunge Test", Factory Mutual Research Corporation Report, FMRC 22485, Norwood, MA, 1976.

2. Heskestad, G. and Bill, R.G., "Modeling of Thermal Responsiveness of Automatic Sprinklers", Fire Safety Science - Proceedings of the Second International Symposium, Hemisphere Publishing Corporation, New York, NY, 1988, pp. 603612.

3. Yao, C., "Overview of Sprinkler Technology Research", Fire Safety Science Proceedings of the Fifth International Symposium, International Association for Fire Safety Science, Bethesda, MD, 1997, pp. 93-110.

4. Eckert, E.R.G. and Drake, R.M., Analysis of Heat and Mass Transfer, McGraw Hill, New York, NY, 1972, p. 501.

5. Zukauskas, A., and Ziugzda, J., Heat Transfer of a Cylinder in Crossflow, Hemisphere Publishing Corporation, New York, NY, 1985, pp. 138-140

6. Grissom W.M. and Wierum F.A., "Liquid Spray Cooling of a Heated Surface", International Journal of Heat and Mass Transfer, 24: 261-271 (1981).

7. Paleev, I.I \& Filippovich, B.S., "Phenomena of Liquid Transfer in Two-Phase Dispersed Annular Flow", International Journal of Heat and Mass Transfer, 9. 1089-1093 (1966).

8. Berry, M.R. Jr. and Goss, W.P., "An Integral Analysis of Condensing Annular-Mist Flow", AIChE Journal, 18: 754-761 (1972).

9. Aihara, T. and Fu, W.S., "Effect of Droplet-Size Distribution and Gas-Phase Flow Separation Upon Inertia Collection of Droplets by Bluff-Bodies in Gas-Liquid Mist Flow", International Journal of Multiphase Flow, 12: 389-403 (1986).

10. Ruffino P., "Measurement of Temperature in a Hot Gas Laden With Water Droplets", Ph.D. dissertation, University of Maryland, College Park, MD, 2001

11. Adrian, R.J., "Particle-Imaging Techniques for Experimental Fluid Mechanics", Annual Review of Fluid Mechanics, 23: 261-304 (1981).

12. Kuo, K.K., Principles of Combustion, John Wiley and Sons, New York, NY, 1986, pp. 370-374.

13. "Standards for Automatic Sprinklers for Fire-Protection Service", Underwriter Laboratories Inc., UL199 $8^{\text {th }}$ ed., Northbrook, IL, 1992, Sect. 19.

14. Bete Fog Nozzles Inc., Nozzle Specifications, Greenfield, MA, 1999. 